\title{
Que saúde para o séc. XXI ?
}

José Manuel Pureza*

\section{RESUMO}

Porque, ao ser a mesma de sempre, a saúde não é menos do que exigência de mudança radical na economia, na política e na cultura. No ano de 1948, a Organização Mundial de Saúde viu incluída na sua carta constitutiva uma definição de saúde como «um elevado padrão de saúde física, mental e bem-estar e não apenas a ausência de doença». Coerentemente, concretizou essa visão ambiciosa no Programa Saúde para Todos até 2000 , enfatizando aí a redistribuição dos recursos mundiais para a saúde e a transformação de gastos militares em despesas de saúde como suportes essenciais de um direito efectivo em escala mundial.

O tempo destas referências parece ter-se desvanecido. Ao primado dos direitos substituiu-se o dogma do encurtamento do Estado e dos gastos sociais. É uma cultura pobre e uma visão estreita da saúde. Mas não é sábia. E sobretudo não é atenta - deliberadamente ou não - às determinantes da saúde. Não é uma cultura de lutadores mas uma cultura de funcionários. Mas, neste tempo de império dos indicadores estatísticos, a saúde persiste em ser um complicador que não se deixa confinar às percentagens.

Em contraponto a essa visão reducionista, existe um outro olhar, personalizado, integral e participativo o da «clínica geral». Se assim for, a clínica geral, com a componente personalizada e a componente comunitária, é a matriz da saúde para o século XXI. Tal como o foi, afinal, em todos os séculos até aqui.

Palavras-Chave: Sociologia; Saúde; Clínica Geral.

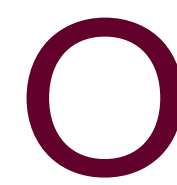

criminoso volta sempre ao local do crime. Revelando uma tremenda irresponsabilidade, tive a ousadia, em Março, de partilhar em voz alta perplexidades e inquietações sobre a função social dos serviços de saúde com os médicos de clínica geral e familiar reunidos no seu $25^{\circ}$ encontro nacional. Não contente com essa desfaçatez, eis-me aqui hoje, perante uma plateia qualificada de médicos, a repetir o atrevimento e a falar sobre saúde. O grande culpado é o José Augusto Simões, meu companheiro de liceu no José Falcão e numa fabulosa equipa de futebol, o «Dínamo de Montes Claros», que treinou umas férias inteiras, fez um jogo particular no velho Campo de Santa Cruz e se finou logo a seguir ao chuveiro.

Há dias, pedi conselho a um amigo sobre o que deveria responder, numa conferência que estava a preparar, à pergunta «que espiritualidade para o século XXI?». A resposta do meu amigo desarmou-me: «a espiritualidade para o século XXI é a mesma de sempre». Estou tentado a dizer exactamente o mesmo acerca da saúde: a saúde no século XXI será a mesma de sempre. E isso, longe de resolver o assunto, torna-o muito mais

*Prof. Associado da Faculdade de Economia da Universidade de Coimbra complexo e difícil. Porque, ao ser a mesma de sempre, a saúde não é menos do que exigência de mudança radical na economia, na política e na cultura. Encaro a saúde assim, como aquilo a que alguém chamou «o silêncio dos órgãos». E essa visão sábia das coisas a que eu adiro traz consigo uma compreensão muito exigente da saúde, vendo-a como a resultante sistémica de condições económicas, sociais, ambientais e até políticas de vida quotidiana.

Sopram hoje, e há cerca de três décadas a esta parte, ventos adversos sobre o barco destemido que é o dos lutadores e lutadoras coerentes e radicais pela saúde, vista assim. A um ciclo de afirmação do bem-estar como síntese da garantia dos direitos humanos fundamentais e à sua expressão nas políticas do significativamente chamado Estado de bem-estar social (welfare state), seguiu-se um outro ciclo, no qual estamos a viver desde a década de 80 - talvez em breve se confirme se estes dias de crise profunda do capitalismo especulativo são ou não os dias do fim desse ciclo - em que a nota dominante tem sido a da retracção dos direitos às mãos quer de um credo ideológico que endeusa o mercado como princípio regulador da totalidade das vidas, quer de medos que reclamam derivas securitárias. No plano da saúde como em diversos outros domínios sociais, 
viemos de um tempo de direitos para um tempo de tecnocratização desumanizada e de empresarialização privatizada.

Vale a pena, por isso, voltar ao tempo da abertura entusiasmada à afirmação da saúde como um direito de todos, como bem público de primeira importância. A Declaração Universal dos Direitos Humanos, de 1948 (estamos em vésperas de comemorar o sexagésimo aniversário), estabeleceu no seu artigo $25^{\circ} \mathrm{o}$ direito de todo o ser humano «a um nível de vida adequado que lhe assegure, assim como à sua família, saúde e bem-estar, e em especial a alimentação, o vestuário, a habitação, a assistência médica e os serviços sociais necessários (...)». Nesse mesmo ano de 1948, a Organização Mundial de Saúde viu incluída na sua carta constitutiva uma definição de saúde como «um elevado padrão de saúde física, mental e bem-estar e não apenas a ausência de doença». Esta visão do direito à saúde como direito positivo e não apenas como ausência de doença, esta ambição de lhe emprestar uma força federadora de requisitos sociais básicos foi plenamente materializada em Alma-Ata. A Declaração Final da Conferência Internacional sobre Cuidados de Saúde Primários, organizada pela OMS em 1978, retomou essa perspectiva agregadora e transversal do direito à saúde, dizendo dele que se trata de «um objectivo social ao nível mundial, cuja realização requer a acção de muitos outros actores sociais e económicos para além do sector da saúde». Alma-Ata veio pois coroar um tempo de distanciamento face aos entendimentos curtos da saúde, limitados às dimensões médicas e sanitárias, e contrapôs-lhes a pertença da qualidade material, social, política e económica das populações ao núcleo mesmo do direito à saúde. Coerentemente, concretizou essa visão ambiciosa no Programa Saúde para Todos até 2000, enfatizando aí a redistribuição dos recursos mundiais para a saúde e a transformação de gastos militares em despesas de saúde como suportes essenciais de um direito efectivo em escala mundial.

O tempo destas referências parece ter-se desvanecido. Ao primado dos direitos substituiu-se o dogma do encurtamento do Estado e dos gastos sociais (perdoem o à parte, mas, mesmo para os mais crédulos, os últimos dias e as suas injecções trilionárias salvadoras da banca e das bolsas vieram provar, se ainda era necessário, que o argumento da míngua de recursos públi- cos para as políticas sociais era uma inverdade estrategicamente sacralizada). Ao primado do bem-estar como resultante agregada de diversas políticas públicas de transformação social contrapôs-se a lógica imediatista da resposta, ainda que preventiva, a pandemias ou do socorro em emergências. Definitivamente, a medicalização das terapêuticas veio ocupar o lugar da ambição sistémica da luta pela qualidade da condição humana.

A própria OMS foi tragada nessa viragem. O seu anterior papel de definição de princípios, de parâmetros e de políticas consequentes com eles, guiadas pelo imperativo da universalidade, passou a ser desempenhado pelas instituições financeiras, ficando a OMS confinada a uma abordagem medicalizada de doenças (re)emergentes e a um aconselhamento técnico aos definidores de políticas, incluindo o Fórum Económico Mundial de Davos e o G8. Ao primado da governação global da saúde pela OMS sucedeu, pois, o protagonismo prático das organizações financeiras como o Fundo Monetário Internacional ou o Banco Mundial. A Alma-Ata opôs-se Wall Street. Em Portugal, o ícone desta mudança foi o da conhecida confissão de uma alta figura de um grupo financeiro que, com uma franqueza digna de elogio, afirmou friamente que melhor negócio que a saúde só mesmo o de tráfico de armas.

É neste contexto de entendimento dominante da saúde como objecto de negócio que as políticas de reconfiguração dos serviços públicos de saúde estão a ser percebidas pelos cidadãos. E o que perpassa pelas experiências quotidianas dos cidadãos comuns - ainda que, tantas vezes, sob o disfarce de rebuscadas retóricas justificativas - é que estamos em pleno tempo de viragem de uma cultura de direitos para uma cultura mercantil. Dito pelas palavras simples dos cidadãos comuns: estamos a ser privados de direitos iguais de todos e somos depois forçados a negociar a compra dos mesmos bens ou serviços, o que nos diferencia em função do nosso rendimento. Num país, o nosso, que chegou tragicamente tarde à cultura de direitos - quer civis e políticos quer, sobretudo, económicos, sociais e culturais - a opacidade técnica e financeira esconde para muitos - aqueles para quem a aquisição onerosa de um cuidado de saúde de qualidade não é, na prática, uma alternativa verdadeira - uma operação de privação do pouco que conseguimos ter como bem co- 
mum. A fragilidade da cultura cívica dos bens públicos em Portugal - na saúde como na educação ou na cultura - facilita enormemente a penetração das retóricas de serviço a uma racionalização que, em bom rigor, é na essência uma miniaturização do serviço público.

Tenhamos pois consciência da história das coisas. É tentador o convite a ignorá-la, porque assim fica mais fácil acreditarmos preguiçosamente que a História acabou e que não há alternativas ao que está e que, supostamente, durará para todo o sempre, não tendo nós mais do que tentar melhorar detalhes funcionais sem tocar na essência. Pelo meu lado, insisto teimosamente em não me resignar a esse canto de sereia. Olho atentamente para a História e avalio as mudanças ocorridas. Não para as contemplar mas para sobre elas agir.

De direito síntese de direitos, a saúde passou a ser definida pelos produtores do saber dominante como sector de actividade, sujeito como os outros aos ditames da rentabilidade. Mudou a filosofia, mudou a ambição, mudaram os protagonistas. Ao ciclo dos lutadores segue-se agora o ciclo dos técnicos e dos accionistas. Sim, a saúde é também aquilo que os seus profissionais querem que ela seja. O meu atrevimento não tem mesmo limites: permitam-me que, não sendo médico, fale brevemente de vós como expoentes de uma cultura de saúde.

Nas sociedades modernas, tão arrogantes como frágeis, os profissionais de saúde são olhados como os últimos garantes da salvação. E, por sua vez, as políticas de saúde deixaram-se aprisionar nesse convencimento social de que haverá, em última instância quem nos livre dos sofrimentos e das inseguranças. Os sistemas de saúde tornaram-se tecnologias supostamente infalíveis onde tudo o resto - a política, a economia, a urbanização - falha cada vez mais. Assumindo essa promessa, os sistemas de saúde dos países ricos apetrecharam-se de sofisticados meios tecnológicos para desempenharem essa função (médico que não requeira dois ou três meios complementares de diagnóstico arriscase a ser processado por negligência!...). O mecanicismo positivista que espartilha o doente numa soma desintegrada de sistemas de músculos, ossos e funções tornou-se numa cultura. Perdidos no labirinto de especialidades hospitalares ou na esquizofrenia entre a consulta pública e o consultório privado do mesmo médico, os cidadãos doentes, e com eles toda a sociedade, adquirem fatalmente da saúde uma compreensão estritamente biofísica e fragmentada.

É uma cultura pobre e uma visão estreita da saúde. Pode ser uma boa área de negócios e sustentar teses de doutoramento e consultorias. Mas não é sábia. E sobretudo não é atenta - deliberadamente ou não - às determinantes da saúde. E, por isso, não é corajosa. Não é uma cultura de lutadores mas uma cultura de funcionários. Zelosos, cumpridores, mas funcionários. Já não é tempo de Joões semana, pois não. Mas, neste tempo de império dos indicadores estatísticos, a saúde persiste em ser um complicador que não se deixa confinar às percentagens. A atenção ao todo de cada um e de cada uma, o sábio olhar que vê em cada homem e em cada mulher muito mais do que uma soma de sistemas orgânicos - a lucidez de juntar precariedade laboral com taquicardia, pobreza com asma, ou desemprego com depressão - são desafios que não cabem nos indicadores de desempenho que fazem as delícias dos gestores de recursos humanos. Disse-o aos vossos colegas reunidos em Março no Algarve e insisto em dizê-lo aqui também: há por aí um tremendo défice, muito, muito maior que o das contas públicas, e que aguarda que alguém tenha a coragem de o denunciar como o maior dos monstros sempre a engordar: é o défice de personalização das políticas. Maria de Lurdes Pintasilgo chamou a essa coisa que está em falta uma ética do cuidado. Mas há um outro défice, não menos importante, que importa colmatar. É o défice da medicina comunitária. Diante dos desafios do mundo turbulento e triturador em que estamos, temos que ser capazes de desenvolver ao mesmo tempo dinâmicas só aparentemente contrárias: a da saúde personalizada e a da saúde pública, fortemente articulada com a educação para a cidadania e com a participação cidadã.

Talvez se chame a esse olhar personalizado, integral e participativo «clínica geral». Se assim for, a clínica geral, com a componente personalizada e a componente comunitária, é a matriz da saúde para o século XXI. Tal como o foi, afinal, em todos os séculos até aqui.

\section{ENDEREÇO PARA CORRESPONDÊNCIA}

José Manuel Marques Silva Pureza

Faculdade de Economia da Universidade de Coimbra

Av. Dias da Silva, 165

3004-512 Coimbra, Portugal 


\begin{abstract}
While always remaining the same, health stands for no less than a demand for a radical change in the economy, in politics and culture. In 1948, the World Health Organization included in its constitution a definition of health as «a high standard of physical and mental health and well-being and not merely the absence of disease.» Consistently, this ambitious vision materialized in the program Health for All by 2000 , which emphasized the redistribution of global resources for health and the conversion of military spending into expenditure on health as the basis for a right effective on a global scale.

The time of these references seems to have waned. The primacy of rights has been replaced with the dogma of the lessening of the State and social expenditures. We stand before a feeble culture and a narrow point of view on health. It is an unwise culture and, above all, one that does not - deliberately or not - have regard for the determinants of healthcare. It is a culture not of struggling people but of officials. However, in this time of domineering statistical indicators, health continues to be a complicating element that shuns the realm of percentages.

This reductionist view is counterpointed by the personalized, integrated and participatory view of the General Practitioner. If so, General Practice, with the Customized and Community components, is the array of health for the twenty-first century. Just as it has been all through the ages.
\end{abstract}

Keywords: Sociology; Health; General Practice. 